\title{
El Sistema General de Regalías
}

\section{Jaime Ramírez Plazas*}

\section{RESUMEN}

El presente ensayo pretende explicar los fundamentos y contenidos del Acto legislativo No 5 de 2011 por medio del cual se modificaron los artículos 360 y 361 de la Carta Política colombiana y se estableció el Sistema General de Regalías, a la cual accederán todas las entidades territoriales y se definen la utilización para nuevos sectores recalcando también los principios de eficiencia y de racionalidad en el gasto como parte elemental del concepto de buen gobierno.

\section{PALABRAS CLAVE}

Regalías, distribución, desarrollo.

\section{ABSTRACTS}

This essay seeks to explain the rationale and contents of the Legislative Act No. 5 of 2011 by which amended Articles 360 and 361 of the Constitution and established Colombian General Royalties System, which will access and all local authorities and use to define new areas also stressing the principles of efficiency and rationality in spending as a basic part of the concept of good governance.

\section{KEYWORDS}

Royalties, distribution, development.

\footnotetext{
* Profesor de tiempo completo de la Universidad Surcolombiana, Profesor catedrático de Posgrado de la Escuela Superior de Administración Pública -ESAP, Economista de la Universidad de los Andes, con Posgrados en Alta Gerencia-Universidad Surcolombiana, Instituciones Jurídicas Político y Derecho Público, de la Universidad Nacional y Docencia Universitaria de la Universidad Antonio Nariño, Maestría en Derecho Económico de la Universidad Externado de Colombia y estudiante del doctorado en Sociología jurídica e Instituciones Políticas de la misma Universidad. Autor de los siguientes libros: Economía Política, Economía e Instituciones Públicas, Evaluación de los Planes de Desarrollo de Neiva- 1988-2003, Estatuto de Contratación de la Administración Pública, Introducción a la Formulación y Evaluación de Proyectos, Las Finanzas Públicas en Colombia, La Hacienda Pública en Colombia, Manual de Control Presupuestal, Microeconomía para Todos, Macroeconomía Para Todos, 115 preguntas sobre el Ajuste Fiscal, Segunda Recopilación de Costumbres Mercantiles en Neiva y Planeación, Presupuesto y Contratación Municipal, Legitimidad del Estado, legalidad y seguridad democrática, y la Relación derecho-economía.
} 


\section{INTRODUCCIÓN}

En los años recientes el auge de la producción minera se ha presentado en un contexto externo favorable, de altos precios internacionales de los bienes básicos y flujos de inversión hacia América Latina. Esto ha permitido que dicha actividad mantenga condiciones positivas para su expansión en el mediano plazo. De hecho, se tiene previsto que durante los próximos 5 a 10 años los niveles de inversión en la actividad minera en Colombia tengan un incremento significativo, lo cual implicaría mayores niveles de producción y de ingresos para el país.

Teniendo en cuenta que un aumento de los ingresos obtenidos en la explotación de recursos naturales no renovables tiene serias implicaciones tanto a nivel macroeconómico como regional, es importante determinar los mecanismos apropiados para la estabilización de dichos ingresos y una estrategia de política económica para establecer vínculos con los demás sectores productivos, que redunden en mayores niveles de crecimiento económico.

Colombia se enfrenta en la actualidad a crecientes posibilidades de generación de una bonanza de ingresos, por cuenta de la expansión de la actividad mineroenergética. Si los agentes económicos no conciben este fenómeno como temporal, y no toman iniciativas de ahorro para usar una parte de esos recursos en épocas de escasez, se generarán efectos desestabilizadores sobre la economía colombiana que la harán vulnerable.

Para cumplir con este objetivo de suavizar el ciclo de los ingresos minero energéticos, el Gobierno Nacional propuso la creación del Sistema General de Regalías (SGR) y, al interior del mismo, de un fondo de ahorro administrado por el Banco de la República, que se alimentará de los ingresos por regalías que excedan la senda de largo plazo expuesta en este documento. Así mismo, cuando estos ingresos caigan por debajo de dicha senda, el fondo desacumulará recursos para financiar proyectos públicos y mantener a través del tiempo una senda estable de gasto.

\section{EL AUGE MINERO ENERGÉTICO Y SUS EFECTOS MACROECONÓMICOS}

\subsection{Efectos macroeconómicos de una bonanza de productos básicos}

\subsubsection{Experiencia internacional en manejo de bonanzas de recursos naturales.}

La evidencia histórica en países en desarrollo muestra que un manejo inadecuado de los ingresos provenientes de recursos naturales, particularmente en épocas de bonanza, ha producido significativas apreciaciones del tipo de cambio y desequilibrios macroeconómicos. Los ejemplos de países en desarrollo que han desperdiciado la riqueza de sus recursos naturales abundan. En África y América Latina, los recursos mineros y agrícolas muchas veces no se han transformado en motores de crecimiento; y en algunos casos han sido causantes de volatilidad 
macroeconómica y estancamiento del resto del aparato productivo, en un fenómeno conocido como "la maldición de los recursos naturales".

Muchos estudios revelan que los países en desarrollo ricos en recursos naturales, han registrado tasas de crecimiento menores que las de otros países en desarrollo. La evidencia empírica e histórica muestra que los recursos naturales promueven el desarrollo económico sólo cuando se combinan con la acumulación de conocimiento para la innovación tecnológica. Por ejemplo, en América Latina no se presentaron las condiciones adecuadas que promovieron el crecimiento económico en economías con amplios recursos naturales como Australia y los países de la península Escandinava debido a una débil conversión tecnológica. En particular, dicha situación se presentó por una deficiente capacidad de aprendizaje y de innovación ante una baja inversión en capital humano y de infraestructura científica (Lederman y Maloney, 2007).

La incidencia de la riqueza obtenida de la explotación de los recursos naturales tiene un efecto positivo en la economía dependiendo de la disponibilidad de capital humano. A medida que el capital humano aumenta, se potencia el efecto positivo y de largo plazo sobre el ingreso. La solución para el lento crecimiento en las economías con amplios recursos naturales, es combinar el capital humano y la adquisición de nuevo conocimiento con la riqueza generada por los recursos naturales.

Así mismo, la concentración de los ingresos de un país particularmente en materias primas (denominados "commodities") como el petróleo y el carbón, ha estado ligada históricamente a la excesiva acumulación de deuda pública cuando los precios internacionales del producto son altos, y al posterior declive económico cuando los precios disminuyen.

Es claro que la adecuada explotación de los ingresos provenientes de los recursos mineros y agrícolas, debe enmarcarse dentro de una política que permita el desarrollo del capital humano y de los demás sectores de la economía. La diversificación del aparato productivo es un elemento clave del desarrollo y de la estabilidad macroeconómica.

Cabe anotar que en la experiencia internacional, aumentos en la riqueza por recursos naturales, han generado debilidades institucionales debido a la presión que ejercen diversos grupos sociales para apropiarse de las rentas generadas por dichos recursos, lo cual resalta la importancia del diseño de la política de ahorro y gasto de los mismos para reducir estas vulnerabilidades (Tomell y Lane, 1999).

Por todo lo anterior, un manejo fiscal prudente de los ingresos extraordinarios de recursos naturales resulta fundamental para fortalecer el ahorro público y privado, y reducir la dependencia del financiamiento interno y externo. De lo contrario, en momentos difíciles, cuando más se requiere de financiación para sostener los niveles de gasto, puede ocurrir que los mercados financieros cierren la disponibilidad de crédito para el país o endurezcan sus condiciones financieras. 
En ese momento, la política fiscal pierde la capacidad de jugar un papel estabilizador del ciclo económico (lo que se conoce como efecto contra-cíclico en la jerga económica), y al contrario puede profundizar la magnitud y la duración de la desaceleración económica, con todos los efectos sociales que ello puede acarrear. Por lo tanto, en la medida en que la asignación responsable de recursos como las regalías asegure la sostenibilidad fiscal, mayores serán las posibilidades de hacer efectivos los derechos sociales, económicos y culturales contemplados en la Constitución Política, y aumentará igualmente el número de personas con acceso a los bienes y servicios básicos.

La adopción de una reforma al actual Régimen Constitucional y Legal de Regalías establece mecanismos de ahorro y distribución acordes con el nuevo escenario de producción minero-energética en el país y fortalecería los alcances que tendrían los Gobiernos subnacionales en su desarrollo económico y lucha contra la pobreza. Ello complementa la estrategia del Gobierno Nacional para fortalecer las finanzas públicas mediante la adopción de una regla fiscal a través del acto legislativo No 3 de 2011, que permite ahorrar parte de los recursos excedentarios de dicha actividad y garantizar un manejo contra-cíclico de la política fiscal, lo cual favorecerá la estabilidad macroeconómica del país.

Una bonanza puede generarse por choques en la producción y/o en los precios de los bienes primarios, y puede afectar el desempeño de una economía a través de varios canales. El más reconocido es el llamado canal cambiado, el cual tiene origen en la entrada masiva de recursos externos (divisas) generados tanto en las inversiones que se realizan en la actividad en expansión como en la venta de los bienes primarios al exterior, todo lo cual tiende a revaluar el tipo de cambio. Es importante mencionar que las expectativas que se generan por dicha revaluación, tienden a acentuar el fenómeno.

El segundo canal de transmisión macroeconómica puede provenir del "efecto ingreso" derivado del aumento en la producción y en el mejoramiento de los términos de intercambio. El mayor ingreso conduce a un aumento del consumo interno tanto del sector público como del privado. En particular, si se asume que la oferta de los bienes no transables (v.gr. servicios) no varía en el corto plazo, y que los precios de los bienes transables (aquellos expuestos a la competencia externa) vienen dados por el mercado internacional, se espera que el aumento en la demanda por el choque externo termine incrementando el precio de los bienes no transables, lo cual genera una apreciación de la tasa de cambio real que retroalimenta el deterioro de la cuenta corriente.

Además, en la medida en que los agentes interpreten esto como un fenómeno permanente, esta dinámica termina incidiendo negativamente en la producción distinta a la de los sectores que son objeto del auge, pues los recursos comienzan a asignarse de manera prioritaria a los sectores objeto de la bonanza. Es así como se llega a lo que tradicionalmente se conoce como el fenómeno de la "enfermedad 
holandesa". Al respecto, se puede observar el artículo "Vacunas contra la enfermedad holandesa" publicado en la revista Carta Petrolera (Cuintaco, 2010).

Un tercer canal de transmisión se desprende de la mayor volatilidad macroeconómica que genera la bonanza minero-energética. Un choque en la producción y/o en los precios de un bien básico puede aumentar de manera significativa la volatilidad macroeconómica. El aumento inicial en la tasa de ahorro de la economía tanto del sector público como del privado, debido a un aumento significativo en los ingresos y su posterior disminución una vez la bonanza se diluye, profundizan el periodo de recesión debido a la no prevención sobre la transitoriedad del auge de ingresos.

La experiencia internacional y de Colombia en episodios de bonanza externa, ha mostrado por ejemplo, que los Gobiernos tienden a aumentar el gasto en inversión y a endeudarse, patrocinados por condiciones favorables de acceso al crédito. Sin embargo, una vez desaparece esa fuente de ingresos, por efecto de caídas de la producción o de precios domésticos o internacionales, el acceso a los mercados de créditos se cierra. Dado que el sector público no cuenta con ahorros por su decisión de gastarse la bonanza, sobreviene un fuerte ajuste y recesión generando un efecto adverso sobre el bienestar de la población, en especial de la más vulnerable. (Echeverry, 2002).

Una publicación reciente que analiza los efectos de las medidas de disciplina fiscal en Chile, muestra evidencia de que ellas redujeron de manera importante la volatilidad macroeconómica en ese país con los evidentes beneficios para un desempeño económico sostenido (Larrain y Parro 2006). Como lo ha mostrado la evidencia internacional, la volatilidad macroeconómica trae consecuencias negativas para el crecimiento económico de largo plazo (Loayza et. al., 2007; Loayza y Hnatkovska, 2004; Ramey y Ramey, 1995).

Un cuarto canal de transmisión económica se refleja a través de las cuentas fiscales, especialmente cuando se trata de choques que afectan los recursos del subsuelo, que son propiedad del Estado.

Inicialmente la bonanza se traduce en un aumento de los ingresos públicos y en un aumento del gasto. Sin embargo, mientras los ingresos son transitorios, por la naturaleza temporal del choque, el mayor gasto se suele volver permanente, con lo cual se puede generar un desequilibrio fiscal de tipo estructural. Esta dinámica se da en contra del precepto sano de ahorrar los ingresos extraordinarios en los períodos de bonanza, con el fin de mitigar los efectos negativos de las crisis.

Los cuatro canales expuestos indican que es fundamental que se dé un uso apropiado a los ingresos extraordinarios que se espera recibir, con el fin de evitar los efectos adversos que se presentan en la destorcida de una bonanza mineroenergética. 
Como se deriva de la sección anterior, ante un panorama de fuerte expansión de la actividad minero-energética, el ahorro de los recursos excedentarios que se generen no sólo en las cuentas del Gobierno Nacional Central sino también en las regiones, debe contribuir en buena medida a moderar los efectos que se podrían generar sobre la estabilidad macroeconómica del país y el bienestar de la población, en especial, las presiones a la apreciación del peso. De esta manera ayudaría a prevenir el peligro de distorsiones económicas que conduzcan a un fenómeno del tipo de "enfermedad holandesa".

\subsection{La experiencia de Colombia en el manejo de las bonanzas}

Colombia ha enfrentado períodos de bonanza asociados con aumentos en las exportaciones de productos básicos, generadas por inesperados aumentos en precios y/o la producción. En varios de esos episodios, la inadecuada administración de los recursos de las bonanzas y la falta de coordinación en las medidas de política económica, llevaron al debilitamiento de la economía, la apreciación real del peso y fuertes reducciones en la tasa de ahorro del país.

Esto en conjunto, vulneró las condiciones de la economía para enfrentar el fin de las bonanzas externas que finalmente sobrevino, lo cual terminó desencadenando profundas recesiones en los períodos posteriores al boom. Son experiencias que el país no debe repetir en beneficio de su estabilidad económica y del bienestar de su población. La bonanza cafetera de 1977 y la expansión de la producción petrolera a partir de 1987 representan los dos casos más significativos y recientes en la economía colombiana, asociados con el comportamiento de los mercados internacionales de materias primas (commodities) o productos agrícolas básicos

\section{La bonanza cafetera de 1977}

Previo a la bonanza de los años setenta, el sector cafetero experimentó una crisis promovida por la reducción del precio internacional del café que se venía presentando desde el año 1957, el cual llegó a los 40 centavos de dólar por libra durante los años 60, luego de haber registrado precios por encima de 50 centavos durante la década de los 50 . Esta crisis generó el deterioro de la balanza de pagos del país y una desaceleración de la actividad económica, particularmente entre 1957 y 1958, e influyó en el comportamiento de la inflación, que pasó de niveles inferiores a 10\% a un promedio de 16\% entre 1963 y 1966 (Junguito, 1996).

Las heladas que afectaron los cultivos de café en Brasil a mediados de la década de los setenta, dieron lugar a un aumento del precio del café colombiano. La bonanza se reflejó en un crecimiento del precio desde 40 centavos de dólar por libra a principios de la década, a 236 centavos en 1977. El precio se mantuvo por encima de 160 centavos hasta finales de la década de los 80. Las exportaciones de café aumentaron de un valor de US $\$ 300$ millones anuales al inicio de los años setenta, hasta US\$2.000 millones en 1979. 
En términos reales, el valor de las exportaciones de café se incrementó a un ritmo promedio de $25 \%$ anual entre 1975 y 1979, mientras que en el mismo periodo las exportaciones industriales apenas crecieron a un promedio de $3 \%$ real. La tasa de cambio real disminuyó paulatinamente a lo largo de la década, como consecuencia de la inflación y de la relativa lentitud en el ajuste de la tasa de cambio nominal bajo el sistema de mini-devaluaciones, que sólo permitía cambios moderados de la tasa de cambio nominal.

Los esfuerzos por disminuir el consumo público al comienzo de la bonanza, permitieron al Gobierno alcanzar superávit fiscales entre 1976 y 1978, pero a partir de 1979 se registró déficit, y el consumo público aumentó por encima del promedio de la década anterior. Entre 1973 y 1977, el ahorro público aumentó de 3\% a 7\% del PIB, lo cual contribuyó al ahorro total nacional, que pasó de $18 \%$ del PIB a $22 \%$ en ese período. A partir de 1977, el ahorro público se redujo considerablemente como proporción del PIB, con lo cual la tasa de ahorro total de la economía se redujo de 22\% del PIB a 15\% del PIB entre 1977 y 1982.

La liberalización de importaciones se dirigió a cerrar la brecha entre la demanda alimentada por el influjo de divisas y la oferta de estos bienes. La contracción monetaria por su parte dirigió esfuerzos a esterilizar el efecto de la acumulación de reservas. A pesar de los esfuerzos, la inflación estuvo por encima del $20 \%$ en promedio en la segunda mitad de los setenta y en la década siguiente. Esto, según lo encontrado por Montenegro (1996) y Urrutia y Suescún (1993), es evidencia de que la bonanza cafetera produjo "Enfermedad Holandesa" en dicho período.

Como consecuencia, entre 1982 y 1985 Colombia vivió una recesión, acompañada de pérdida de reservas internacionales, quiebra de empresas, aumento en el desempleo, crisis bancaria y una fuerte devaluación de su moneda.

La bonanza petrolera en la década de los ochenta y noventa

El descubrimiento de yacimientos como Caño Limón (1983), Cusiana (1988) y Cupiagua (1993) incrementó significativamente el ingreso petrolero de la Nación, y se reflejó en un aumento considerable del gasto público, particularmente desde la segunda mitad de los noventa, no sólo a nivel del Gobierno Central sino también en los departamentos y municipios, cuyos ingresos por concepto de regalías aumentaron por efecto de la bonanza. Así mismo, aumentó la deuda de todos los niveles de Gobierno, alentada por los nuevos descubrimientos petroleros.

Con la entrada en operación de Caño Limón, en 1987, el valor de las exportaciones de petróleo y derivados aumentó significativamente. Desde principios de los años noventa, cuando ya se había sumado la producción de Cusiana y Cupiagua, el país vivió un nuevo período de auge petrolero y las exportaciones por este concepto, pasaron de US\$ 455 millones en 1986, a US\$2.2 miles de millones en 1995. 
Los nuevos recursos petroleros permitieron una recuperación del consumo público, de forma que el gasto público mostró aceleraciones entre 1987 y 1989, y luego entre 1994 y 1997, estimulado por el incremento en los ingresos producto del auge en las exportaciones petroleras. Al igual que en el caso del café, la bonanza del petróleo contribuyó a la apreciación real del peso durante los años noventa, y al aumento del gasto no sólo en el sector público sino también en el privado. El ahorro público sufrió una dramática reducción entre 1995 y 1997, pasando del $8 \%$ del PIB a un desahorro equivalente a $0.2 \%$ del PIB. El ahorro del sector privado también se redujo durante la segunda mitad de la década, pasando del 15\% del PIB en 1994 a $11 \%$ en 2000.

Todo ello en conjunto, hizo muy vulnerable a la economía colombiana, pues las bajas tasas de ahorro tanto público como privado, y los altos niveles de endeudamiento, impidieron que la economía pudiera enfrentar la destorcida de 1998 la cual desencadenó en crisis del sistema financiero y recesión económica.

De acuerdo con lo observado en décadas anteriores, Colombia siguió un patrón de comportamiento relativamente similar durante las épocas de bonanza externa, que luego dieron lugar a una fase de desaceleración.

En líneas generales, durante los años de auge hay aumentos en el ingreso disponible, los cuales se perciben como de carácter permanente, que lleva a los agentes incluido el Gobierno, a aumentar su consumo. El efecto inmediato es por un lado, una mayor inflación dadas las presiones de demanda y una apreciación real de la moneda; y por otro lado, una caída en el ahorro de la economía todo lo cual se verá paulatinamente reflejado en un deterioro de la cuenta corriente del país y un alto nivel de endeudamiento.

Una vez la bonanza externa se diluye, las fuentes de ahorro se van extinguiendo, lo mismo que las fuentes de financiamiento, ante la pérdida de credibilidad de los mercados dados los evidentes desequilibrios en los balances de los agentes. Ante el cierre de los mercados y la poca posibilidad de realizar política contracíclica por parte del Gobierno, la economía se enfrenta a una desaceleración que termina en recesión, desempleo, aumento de la pobreza, pérdida de ingreso, quiebras y sufrimiento social.

\section{La bonanza de precios del petróleo entre 2005 y 2007}

El auge de la economía mundial posterior a 2003 creó una demanda de materias primas y combustibles que llevó al precio del petróleo (WTI) a cerca de US $\$ 150$ por barril. Mientras los flujos de divisas del país mejoraron por este concepto, los flujos fiscales no indujeron a un ahorro de estos recursos transitorios.

En síntesis, la experiencia de Colombia en el manejo de bonanzas externas ha demostrado la necesidad de adoptar políticas públicas que permitan el ahorro de parte de los recursos excedentarios, de tal forma que el país pueda mantener el 
gasto a través del tiempo, evitar la enfermedad holandesa, y crear las condiciones para evitar una posterior recesión. El manejo contracíclico de la política fiscal, que involucre tanto al Gobierno Central como a las regiones, permite estabilizar la economía y garantizar un crecimiento económico sostenido.

Este tipo de manejo requiere que los Gobiernos ahorren en períodos de auge y puedan desarrollar en períodos de desaceleración, en beneficio de la población en general y de las regiones y personas más vulnerables en particular. La participación del sector público en el ciclo económico es significativa y la moderación del gasto es clave para evitar los efectos nocivos de una bonanza, con instrumentos tales como la adopción de una regla fiscal o la implementación de un fondo de ahorro y estabilización de recursos extraordinarios.

\section{PRONÓSTICOS DE MEDIANO PLAZO DEL SECTOR MINERO-ENERGÉTICO}

Como se verá a continuación, el boom minero- energético que estaría viviendo Colombia en los próximos años es producto de los posibles aumentos en la producción del sector, más que por los precios de sus materias primas. Por regla, una bonanza externa está asociada con la incertidumbre respecto a su duración y tamaño.

Las previsiones del sector minero-energético para el mediano plazo contemplan nuevos proyectos de generación en gas, energía eléctrica e hidrocarburos, así como la expansión en otros sectores como el de níquel, oro, cobre, polimetálicos, carbón e interconexión eléctrica con otros países (Panamá, República Dominicana y Puerto Rico). De acuerdo con el Ministerio de Minas y Energía, se estima que la inversión en la actividad minera ascienda a US\$57.000 millones entre 2010 y 2015; esto es aproximadamente $20 \%$ del país podría alcanzar niveles cercanos a los 250 miles de barriles equivalentes (KBPDC-E).

La literatura internacional recomienda que el diseño de un fondo de estabilización prevea un escenario probable de ingresos futuros. Por esta razón a continuación se presentan los pronósticos de producción de productos de la minería y del petróleo y sus derivados, los cuales están siempre sujetos a alto grado de incertidumbre.

Con la información disponible actualmente, es posible construir dos escenarios de producción de crudo en el mediano plazo. En el primero, el máximo nivel de producción llegaría a 1.250 miles de barriles diarios (KBPD) en 2015; a partir de ese año se reduciría gradualmente en la medida en que el proceso exploratorio no adicione reservas suficientes de crudo y gas y los campos actuales vayan deteriorando su producción y agotando sus reservas. En un segundo escenario, se prevé una producción que llegaría a cerca de 1.450 KBPD en 2018, como resultado de las inversiones de Ecopetrol en el desarrollo de crudos pesados, incremento en los factores de recobro de campos maduros y éxito en la actividad exploratoria, que le permitirían llevar su producción a 900 KBPD. 
De igual manera, se requerirá un aumento en la producción de crudo por parte de otras empresas que operan en el sector, lo cual se soporta en los contratos suscritos por la Agencia Nacional de Hidrocarburos (ANH) en los últimos tres años, a partir de los procesos de asignación de áreas por el esquema de "primero en el tiempo, primero en el derecho", y a través de las nuevas rondas de asignación de áreas del año 2011 en adelante.

Con base en el segundo escenario mencionado, se calcula que la inversión que se llevará a cabo en el sector de hidrocarburos, especialmente en la exploración, incremento en el factor de recobro de campos maduros y en el desarrollo de los crudos pesados, permitirá un aumento sostenido en la producción de petróleo crudo hasta alcanzar más de 1.4 millones de barriles diarios en el año 2018 \{Cuadro 1). La producción nacional correspondiente a Ecopetrol ascendería a 850 miles de barriles por día calendario (KBPDC) en 2015; si se incluye gas, la producción nacional total de la empresa en barriles equivalentes alcanzaría los 994 KBPDC en dicho año; cabe anotar que este pronóstico no incluye los aumentos en la producción de Ecopetrol provenientes de la compra de activos a la compañía British Petroleum Colombia (BP). Los pronósticos también señalan que la producción de gas del país podría alcanzar niveles cercanos a los 250 miles de barriles equivalentes (KBPDC-Eq).

\section{Cuadro 1. Proyección de producción del sector de petróleo y minería}

\begin{tabular}{|c|c|c|c|c|c|c|c|c|c|c|c|c|}
\hline Recurso & 2011 & 2012 & 2013 & 2014 & 2015 & 2016 & 2017 & 2018 & 2019 & 2020 & cantidad & variación \\
\hline Petróleo(1 & 950 & 1050 & 1150 & 1250 & 1350 & 1400 & 1450 & 1450 & 1450 & 1450 & 650 & $61 \%$ \\
\hline $\operatorname{Gas}(2)$ & 200 & 200 & 250 & 250 & 250 & 250 & 250 & 250 & 250 & 250 & 50 & $25 \%$ \\
\hline Subtotal (3) & 1150 & 1250 & 1350 & 1400 & 1600 & 1650 & 1700 & 1700 & 1700 & 1700 & 700 & $70 \%$ \\
\hline Carbón(4) & 96 & 107 & 119 & 124 & 125 & 138 & 144 & 150 & 152 & 160 & 68 & $74 \%$ \\
\hline Níquel(5) & 37 & 51 & 51 & 51 & 51 & 51 & 51 & 51 & 51 & 51 & 1 & $1 \%$ \\
\hline Oro & 56 & 62 & 69 & 72 & 75 & 80 & 84 & 87 & 89 & 93 & 40 & $74 \%$ \\
\hline \multicolumn{13}{|c|}{$\begin{array}{l}\text { Cifras en miles de barriles diarios } \\
2 \text { Cifras en miles de barriles equivalentes }\end{array}$} \\
\hline \multicolumn{13}{|c|}{3 Cifras en millones de toneladas } \\
\hline $\begin{array}{l}4 \text { Cifras en } n \\
5 \text { Toneladas }\end{array}$ & ones $\mathrm{C}$ & n & & & & & & & & & & \\
\hline
\end{tabular}

Fuente: Ministerio de Minas, DGPM - Ministerio de Hacienda y Crédito Público. Estas proyecciones están sujetas a riesgo exploratorio, especialmente en la actividad de hidrocarburos. Solo deben ser interpretadas y utilizadas como indicadores de una posible tendencia y no como valores establecidos.

Por su parte, los precios externos de los productos básicos son altamente volátiles. Es usual que en las crisis éstos bienes sean utilizados como refugio de valor (evidente en petróleo y oro), por lo que su precio tiende a aumentar sin que ello obedezca necesariamente a las condiciones de largo plazo de sus mercados. Ello hace que la elaboración de pronósticos de precios de commodities sea una tarea particularmente difícil; por lo cual resulta más conveniente consultar las predicciones de las agencias especializadas. Teniendo esto en cuenta, el precio de mediano plazo del crudo colombiano se proyecta ajustándolo a las proyecciones del West Texas Intermedíate (WTI) de las diversas agencias internacionales (Cuadro 2). 
Los pronósticos sobre el precio de exportación del crudo colombiano indican que éste podría crecer gradualmente en los próximos 10 años, pasando de US $\$ 77$ por barril en 2010 a US $\$ 90$ por barril en 2020. Se considera que el diferencial de precio entre el crudo colombiano y el de referencia internacional (WTI) sea, en promedio, de US\$8 por barril.

\section{Cuadro 2. Proyección de precios del sector minero-energético*}

$\begin{array}{lllllllllll}\text { Precios } & 2011 & 2012 & 2013 & 2014 & 2015 & 2016 & 2017 & 2018 & 2019 & 2020 \\ \text { Crudo WTI(1) } & 8 & & 80 & 84 & 84 & 86 & 86 & 88 & 90 & 90 \\ \text { Carbón FOB(2) } & 81 & 82 & 82 & 83 & 83 & 83 & 83 & 83 & 83 & 83 \\ \text { Níquel(3) } & 5 & 5 & 5 & 6 & 6 & 6 & 6 & 6 & 6 & 6 \\ \text { Oro(4) } & 1150 & 1200 & 1250 & 1250 & 1250 & 1250 & 1250 & 1250 & 1250 & 1250\end{array}$

*Estas proyecciones están sujetas a márgenes de error

(1) US/Barril (2) US/tonelada (3) US/libra (4) US/onza

Fuente: Ministerio de Minas, DGPM - Ministerio de Hacienda y Crédito Público y DNP, con base en publicaciones internacionales especializadas.

Por otra parte, los pronósticos sobre la producción de minerales como carbón, ferroníquel y oro muestran una ampliación importante en la mayoría de los casos en los próximos años. Usando información del Ministerio de Minas y Energía, por ejemplo, se estima que la producción carbonífera aumentaría aproximadamente de 92 millones de toneladas en 2010 a 160 millones en 2020. Por su parte, se calculan aumentos anuales promedio alrededor de $6 \%$ en la producción de oro, hasta alcanzar las 93 toneladas en 2020. En el caso del níquel, en cambio, los pronósticos indican que la producción se mantendrá a partir de 2012 alrededor de 50 millones de libras anuales (Cuadro 1).

Los pronósticos de precios de carbón permiten esperar que se registre un aumento hasta llegar a US\$83 por tonelada en 2020. Por su parte el oro podría aumentar a 3.260 mil onzas troy en 2020 . Sus cotizaciones podrían ascender a US\$1.250 en ese año.

Como es de esperarse, la mayor producción y exportación de minerales tendrá un impacto significativo no sólo sobre las cuentas fiscales, por su mayor contribución en el impuesto a la renta, dividendos de Ecopetrol y regalías, sino también sobre la balanza comercial del país. Solamente por cuenta de los ingresos generados por la actividad de Ecopetrol (impuesto de renta más los dividendos de Ecopetrol a la Nación), el Gobierno Nacional podría ver incrementados sus recursos de cerca de $\$ 7.4$ billones en 2011 (1.3\% del PIB), a $\$ 19$ billones en 2021 (valores en pesos corrientes), monto equivalente a $1.6 \%$ del PIB (Cuadro 3). Por cuenta de toda la actividad minera los ingresos de la Nación, pasarían de cerca de $\$ 9.3$ billones en 2011 ( $1.6 \%$ del PIB) a cerca de $\$ 23$ billones en 2021 (2.0\% del PIB). 
Cuadro 3. Proyección de ingresos del Gobierno Nacional generados por la actividad minera*

\begin{tabular}{|c|c|c|c|}
\hline Año* & $\begin{array}{l}\text { Ingresos } \\
\text { provenientes } \\
\text { de Ecopetrol 1/ } \\
\text { Miles de } \\
\text { Millones de } \\
\text { pesos } \\
\text { corrientes }\end{array}$ & $\begin{array}{l}\text { Impuesto de } \\
\text { renta pagado } \\
\text { por el recibo } \\
\text { del sector } \\
\text { minero } \\
\text { Miles de } \\
\text { Millones de } \\
\text { pesos } \\
\text { corrientes }\end{array}$ & $\begin{array}{l}\text { Ingresos } \\
\text { totales } \\
\text { provenientes } \\
\text { del sector } \\
\text { minero } \\
\text { Miles de } \\
\text { Millones de } \\
\text { pesos } \\
\text { corrientes }\end{array}$ \\
\hline 2011 & 7.500 & 1.800 & 9.300 \\
\hline 2012 & 9.000 & 2.400 & 11.400 \\
\hline 2013 & 9.900 & 2.600 & 12.500 \\
\hline 2014 & 11.900 & 2.700 & 14.600 \\
\hline 2015 & 12.200 & 2.700 & 14.900 \\
\hline 2016 & 14.200 & 3.000 & 17.200 \\
\hline 2017 & 14.800 & 3.300 & 18.100 \\
\hline 2018 & 16.200 & 3.900 & 20.100 \\
\hline 2019 & 17.100 & 4.400 & 21.500 \\
\hline 2020 & 18.600 & 4.300 & 22.900 \\
\hline 2021 & 19.000 & 4.000 & 23.000 \\
\hline
\end{tabular}

Fuente; DGPM-MHCP. ${ }^{*}$ Cifras sujetas a revisión. *Proyecciones sujetas a amplio margen de incertidumbre. *Proyecciones sujetas a amplio margen de incertidumbre

1/ Incluyen los dividendos de Ecopetrol que recibe la Nación, asumiendo que se distribuye el 70\%, así como el impuesto de renta pagado por dicha empresa.

Como se expresó anteriormente, las proyecciones de regalías están sujetas a un alto grado de incertidumbre. Bajo un escenario relativamente alto de producción en los próximos diez años, es posible esperar que, en promedio, éstas alcancen un poco más de $\$ 10$ billones durante la década, con un aumento anual promedio de $5 \%$ entre 2011 y 2020 ; lo que significa que podrían tener un incremento de más de $60 \%$ en los próximos 10 años (Cuadro 4).

Cuadro 4. Proyección de regalías del sector minero-energético (Miles de millones de pesos corrientes) ${ }^{*}$

$\begin{array}{lllllllllll}\text { Recurso } & \mathbf{2 0 1 1} & \mathbf{2 0 1 2} & \mathbf{2 0 1 3} & \mathbf{2 0 1 4} & \mathbf{2 0 1 5} & \mathbf{2 0 1 6} & \mathbf{2 0 1 7} & \mathbf{2 0 1 8} & \mathbf{2 0 1 9} & \mathbf{2 0 2 0} \\ \text { Hidrocarburo } & 7290 & 7550 & 8010 & 8100 & 8570 & 8510 & 8750 & 9010 & 9260 & 9540 \\ \text { Carbón } & 1331 & 1339 & 1379 & 1496 & 1501 & 1567 & 1649 & 1695 & 1801 & 2047 \\ \text { Níquel } & 70 & 95 & 95 & 99 & 101 & 104 & 110 & 112 & 121 & 129 \\ \text { Otros } & 143 & 157 & 177 & 188 & 191 & 208 & 224 & 237 & 247 & 272\end{array}$

Fuente: Cálculos DGPM (MHCP) basados en datos de DGPM (MBCP) y DNP

*Esta información está sujeta a amplio margen de incertidumbre y depende de variables como la producción, los precios y el precio de liquidación de las regalías 


\section{MECANISMOS DE AHORRO}

Durante la presente década el incremento en el precio de las materias primas, especialmente de carácter minero, se reflejó en aumentos de los ingresos por exportaciones para los países productores de dichos bienes, lo cual implicó desafíos para las autoridades económicas ante los flujos crecientes de divisas.

El precio internacional de referencia del petróleo (WTI) pasó de US\$ 45 por barril, en promedio durante los años 2004 a 2007, a US\$ 150 por barril a mediados de 2008. Ante dicha situación, los gobiernos recibieron mayores ingresos fiscales por petróleo durante este período de auge de precios internacionales. Incluso, después de la crisis financiera internacional, el precio del petróleo se ha mantenido en un rango entre US\$ 70 - US\$ 80 por barril, desde el segundo trimestre de 2009.

El aumento de los ingresos fiscales de los gobiernos reabrió el debate internacional sobre el manejo de los excedentes que se generen. Entre las alternativas estudiadas para enfrentar tal situación estuvo la creación de fondos de ahorro y estabilización con el objetivo de prevenir los efectos de la llamada "enfermedad holandesa". Adicionalmente, varios países no solamente han acudido al diseño de los fondos de estabilización sino también a la incorporación de reglas fiscales, leyes de responsabilidad fiscal y otras "instituciones fiscales especiales".

Factores como la volatilidad en los precios de las materias primas y la incertidumbre en la duración de la producción de recursos naturales no renovables, justifican la creación de los fondos de ahorro y estabilización, los cuales pueden contribuir a un manejo adecuado de la política fiscal. Precisamente, algunos estudios han señalado que los países que han tenido éxito en el manejo de los excedentes generados en los ingresos mineros y su incidencia en el manejo de la política macroeconómica, han logrado complementar la implementación de los fondos de ahorro y estabilización con una regla fiscal o una estricta programación fiscal de mediano plazo (Shabsigh e llahi, 2007).

Además, la creación de un fondo de ahorro y estabilización permite dedicar parte de este rubro a la inversión (por ejemplo en infraestructura) y a la promoción de ciertos sectores y actividades estratégicas para el desarrollo económico del país.

Cabe anotar que solo algunos países han mantenido un fondo de ahorro y estabilización que han cumplido estándares de transparencia y de coherencia con la política fiscal. Entre los más destacados se encuentran Noruega y Chile, mientras que otras naciones, especialmente del medio oriente, mantienen fondos soberanos de riqueza con recursos petroleros pero no tienen ningún vínculo específico con el diseño de la política fiscal. 


\section{LA REGLA FISCAL SOBRE LAS FINANZAS DEL GOBIERNO NACIONAL CENTRAL}

Colombia ha registrado avances importantes en términos de la sostenibilidad fiscal, no solo a nivel del Gobierno Nacional Central sino también de los gobiernos subnacionales. En lo que respecta a estos últimos, en la segunda mitad de los noventas se aprobó una Ley que supeditó el endeudamiento de los entes territoriales a su capacidad de pago. Luego se tramitó otra con el fin de fijar límites a sus gastos de funcionamiento, lo cual ha contribuido de manera importante en su estabilidad financiera.

En 2003, el Gobierno Nacional dio un nuevo paso al tramitar normas para propiciar la transparencia y responsabilidad fiscal a nivel del sector público. Así mismo, en 2001 se creó el Sistema General de Participaciones que contribuyó a estabilizar los recursos del gasto social y a la meta de estabilidad fiscal y macroeconómica. Se debe mencionar también la creación del Sistema General de Pensiones y su positivo efecto en la equidad y la sostenibilidad del sistema pensional. En su conjunto, estas medidas complementaron otras directrices emanadas de la Constitución Política de 1991, en materia de transferencias de recursos a las regiones y del financiamiento del Gobierno a través del Emisor.

Si bien ha habido mejoras en la normatividad para el manejo sano de las finanzas públicas, aún falta un camino por recorrer que permita blindar el manejo fiscal hacia el futuro, que fortalezca el papel estabilizador de la política fiscal en su conjunto y contribuya a reducir el nivel de la deuda pública. A lo anterior se suma la importancia de dar un manejo responsable a los recursos que se generen por la expansión de la actividad minero energética y que ingresarán tanto a las cuentas de la nación como a las de los gobiernos subnacionales.

La adopción de una regla fiscal tendrá muchos beneficios: permite un espacio para la política fiscal contracíclica, lo cual significa que la autoridad fiscal podrá ahorrar en momentos de auge y desahorrar en momentos de recesión, sin que se comprometa su meta de mediano plazo, contribuyendo así a la estabilidad macroeconómica; garantiza a la población el acceso a los bienes y servicios a los que tienen derecho; permite una mejor coordinación entre la política fiscal y monetaria del país, ya que durante las expansiones de la economía, o bonanzas de un sector específico, la regla promueve una política fiscal de ahorro, apoyando los esfuerzos de estabilización de la autoridad monetaria. Durante las recesiones, la regla permite una política fiscal expansionista y ayuda a la política monetaria en su propósito de estimular la economía a través de menores tasas de interés.

Otra característica importante de la regla es que posibilita un manejo macroeconómico adecuado de los posibles excedentes que genere el sector minero-energético, ya que deberán ser ahorrados cuando existan bonanzas extremas, bien sea a través de un fondo de ahorro o por medio de menor deuda; y podrán ser desahorrados cuando las circunstancias lo requieran. 


\section{EL BALANCE DEL SISTEMA DE REGALÍAS COLOMBIANO}

Las regalías son una contraprestación económica generada en favor del Estado, y las entidades territoriales tienen un derecho económico de participación sobre las mismas. En consecuencia, las regalías las reciben los departamentos y municipios en cuyo territorio se explotan los recursos naturales no renovables y los municipios portuarios por donde se transportan dichos recursos o sus derivados, además de otras entidades territoriales no receptoras o menores beneficiarías a través de la asignación de dineros del Fondo Nacional de Regalías (FNR). También reciben este tipo de recursos algunas Corporaciones Autónomas Regionales, el Fondo Nacional de Pensiones de las Entidades Territoriales (FONPET), Ingeominas, Cormagdalena, y el Fondo de Fomento del Carbón, entre los más importantes.

De acuerdo con las determinaciones legales vigentes, las regalías y compensaciones se distribuyeron en promedio durante el período 1994-2009, de la siguiente manera:

\section{Acumulado 1994-2009}

49\% DEPARTAMENTO PRODUCTOR $\$ 20,5$ bill. Regalías Directas ( $\$ 33,3$ bill.) $23 \%$ MUNICIPIO PRODUCTOR $\$ 9,8$ bill.

$7 \%$ MUNICIPIO PORTUARIO $\$ 3,0$ bill. 21\% FONDO NACIONAL DE REGALÍAS (FNR) $\$ 8,9$ bill. Regalías Directas $(\$ 33,3$ billones.)

TOTAL \$42.2 billones.

El $5 \%$ de las regalías que reciben los departamentos y municipios productores, y el $50 \%$ de las regalías que se asignan al FNR, se destinan al FONPET.

\subsection{Evolución de las regalías}

A partir de la expedición de la Ley 141 de 1994 se evidencia un creciente volumen de regalías generadas por la explotación de hidrocarburos, carbón, níquel y demás recursos naturales no renovables.

Durante el período comprendido entre 1994 y 2009 se han generado regalías cercanas a los $\$ 42.2$ billones a precios constantes de 2009. De las regalías generadas, $\$ 33.3$ billones corresponden a directas y $\$ 8.9$ billones a indirectas.

Del total de regalías directas, las generadas por explotación de hidrocarburos ascendieron en el mismo período a $\$ 27.4$ billones a precios constantes de 2009, que representan el $82 \%$ del giro total, seguidas por las derivadas de la explotación de carbón que correspondieron a $\$ 4.1$ billones, níquel con $\$ 1.1$ billones y otros recursos naturales 24 con $\$ 0.6$ billones, que representaron el $12 \%, 3 \%$ y $3 \%$, respectivamente 
Sin embargo, a pesar del importante peso de las regalías generadas por hidrocarburos, a partir de 2005 se ha venido presentado un aumento significativo de la participación de las regalías generadas por carbón, situación que obedece al importante crecimiento de su producción, especialmente en los departamentos de La Guajira y Cesar.

La distribución de los recursos de regalías directas y compensaciones por beneficiario se concentran en los departamentos, los cuales han percibido el $59 \%$ de las regalías generadas en el período 1994-2009, los municipios el 39\% y las Corporaciones Autónomas Regionales el $2 \%$

Es importante precisar, que de las 790 entidades beneficiarias de recursos de regalías directas, (32 departamentos, 751 municipios y 7 Corporaciones Autónomas Regionales), 17 departamentos y 60 municipios perciben el 95\% de las mismas. Esta concentración se deriva del criterio de asignación de las regalías ligado a la producción. Como resultado de la situación descrita, los principales beneficiarios de estos recursos han sido los departamentos y municipios receptores por explotación de hidrocarburos correspondientes a Casanare, Meta, Arauca y Huila. Para el periodo 1994 a 2009, estos departamentos recibieron el $56 \%$ de las regalías generadas.

\subsection{Consecuencias del actual diseño Constitucional y Legal}

5.2.1 Inequidad y pobreza

La Ley determinó que la distribución de las regalías entre las diferentes entidades territoriales se realizará de acuerdo con el tipo y volumen de los recursos explotados y transportados, sin tener en cuenta criterios como el número de habitantes a beneficiar, el número de personas o familias pobres, los índices de necesidades básicas insatisfechas de dichos habitantes, la capacidad administrativa y financiera de las entidades territoriales y los impactos ambientales. Con el aumento de los precios de hidrocarburos y la producción de carbón a partir del año 2000 , se generó un aumento considerable en la generación de regalías y se hizo manifiesta la excesiva concentración de estos recursos en unas pocas entidades territoriales.

La distribución de participaciones de regalías de hidrocarburos, según lo contemplado en el artículo 27 de la Ley 756 de 2002 se presenta en la Cuadro 5, cuyo volumen depende de los barriles promedio diario mensual BPMD.

Cuadro 5. Distribución de participaciones de regalías de Hidrocarburos

\section{Entidad}

Producción
de
Municipio
$0-10.000$
BPMD (\%)

Producción de
Municipio
10.000-20.000
BPMD (\%)

Producción de Municipio Superior 20.000 BPMD (\%) 


\begin{tabular}{|c|c|c|c|}
\hline $\begin{array}{l}\text { Departamentos } \\
\text { Productores }\end{array}$ & 52 & 47.5 & 47.5 \\
\hline Municipios o Distritos & 32 & 25 & 12.5 \\
\hline $\begin{array}{l}\text { Municipios o distritos } \\
\text { portuarios }\end{array}$ & 8 & 8 & 8. \\
\hline $\begin{array}{l}\text { Fondo nacional de } \\
\text { regalías } \\
\text { Fuente: DNP }\end{array}$ & 8 & 19.5 & 32 \\
\hline
\end{tabular}

La distribución de recursos de regalías con base en el diseño constitucional vigente genera la concentración del $80 \%$ de estos en entidades territoriales que representan el $17 \%$ de la población. Dicha situación produce inequidad en la distribución de una fuente de financiación que debería beneficiar de manera más equilibrada a todas las regiones del país y que afecta la compensación territorial, ya que si bien el Sistema General de Participaciones busca una distribución más equitativa entre las regiones, al incorporar en el balance los recursos de regalías, dicha equidad se ve neutralizada por la desigual distribución de las regalías entre departamentos y municipios.

Cuando el análisis se realiza por departamentos, se encuentran diferencias aún mayores. En Casanare, con menos del $1 \%$ de la población recibe el $24 \%$ de las regalías; Meta con el $2 \%$ de la población el $12 \%$ de las regalías, y Arauca con el $0,5 \%$ de la población el 10,8\%; esta situación genera una gran inequidad difícil de justificar.

Si bien resulta razonable que las entidades territoriales en donde se realizan las actividades extractivas perciban una regalía acorde con los efectos que genera dicha actividad, la asignación no conserva correspondencia con la distribución de la población.

En contraste, departamentos con probadas necesidades de recursos como Chocó y Nariño reciben sumas bajas, lo que históricamente los ha conducido a una trampa de pobreza o a depender de recursos del Gobierno Central exclusivamente.

\section{Pobreza}

Generalmente se utilizan dos indicadores: una Línea de Indigencia (LI) y una Línea de Pobreza (LP). La línea de indigencia se define como el valor de una canasta de consumo que permite a una familia típica cubrir sus necesidades mínimas de alimentación tal y como las define la Organización Mundial de la Salud, es decir, a partir del valor de una canasta de consumo que proporcione alrededor de 2,250 kilocalorías diarias por adulto. Por su parte, a la línea de pobreza moderada se le agrega, además del consumo en alimentos, el valor estimado de todos aquellos bienes básicos no alimenticios. 
De acuerdo con la información de la Misión de Pobreza, para los departamentos en los cuales existe medición de la línea de pobreza en 2005, los departamentos de Santander (49\%) y Meta (45\%) se encuentran por debajo de la línea de pobreza nacional (50\%), en tanto los departamentos de Córdoba $(66 \%)$ y Huila (60\%) presentan los mayores porcentajes de población bajo la línea de pobreza.

Respecto a los cálculos de línea de indigencia, los departamentos de Boyacá (34\%), Córdoba (28\%) y Huila (24\%), presentan los mayores niveles de población ubicada por debajo de la línea de indigencia, por encima del promedio nacional $(15,6 \%)$. Los departamentos de Santander $(14,5 \%)$ y Meta $(12,2 \%)$ tienen una proporción de población por debajo de la Línea de Indigencia menor al promedio nacional $(15,6 \%)$, manteniendo la tendencia presentada en el comportamiento de la línea de pobreza.

En general, los principales departamentos receptores de regalías no han logrado que esta fuente de recursos se convierta en un generador de riqueza en la región como se esperaría, especialmente, en los departamentos de Córdoba y La Guajira en donde se presentan diferencias significativas con departamentos como el Meta.

En estricto sentido, las entidades territoriales beneficiarias de regalías deben alcanzar niveles de bienestar al menos cercanos al promedio nacional, para evaluar los avances obtenidos en materia de mejoramiento de las condiciones de vida de la población. Se analizan a continuación los cambios en los indicadores que permiten medir condiciones de pobreza en el grupo de departamentos que concentran el $80 \%$ de las regalías; ellos corresponden a Casanare, Meta, Arauca, Huila, La Guajira, Santander, Córdoba y Cesar.

De acuerdo con los resultados del Censo 2005, de los ocho departamentos mayores receptores, después de diez años de recibir regalías directas, solamente Meta y Santander presentan un índice de Necesidades Básicas Insatisfechas INBI- inferior al promedio nacional (27,7\%). Adicionalmente, llama la atención el alto INBI en departamentos como La Guajira y Córdoba que supera el $60 \%$, incluso por encima de departamentos como Cauca y Vaupés que no cuentan con una actividad productiva significativa.

Ahora bien, al comparar los avances en materia de reducción de la pobreza en el período 1993 (antes de la recepción de regalías) y 2005, se observa que los departamentos con mayores reducciones del índice pobreza fueron Arauca $(17,8)$ y Casanare $(16,5)$. De otra parte, departamentos como Huila y Córdoba a pesar de haber registrado reducción de su INBI estuvieron por debajo del promedio nacional de 9,43; y en el caso del departamento de la Guajira el índice de necesidades básicas insatisfechas aumentó.

\subsubsection{Ineficiencia}

El marco legal vigente definió como uso prioritario de las regalías la financiación de la prestación de servicios sociales, haciendo especial énfasis en salud, 
educación, agua potable y la reducción de la mortalidad infantil; destinación que sólo podrá cambiarse cuando las entidades territoriales beneficiarias cumplan con las coberturas mínimas en los sectores señalados.

\subsubsection{Las coberturas mínimas}

Uno de los objetivos propuestos desde la expedición de la Ley 141 de 1994 fue promover que los departamentos y municipios receptores de regalías alcanzaran las coberturas mínimas de los servicios en educación, salud, agua potable, alcantarillado y mortalidad infantil. Mientras las entidades territoriales beneficiarias de regalías no alcancen las coberturas mínimas en estos sectores, los departamentos deben asignar por lo menos el $60 \%$ de los recursos de regalías y compensaciones, y los municipios el $75 \%$ de estos recursos, hasta lograr dichos propósitos.

El incentivo para aquellas entidades territoriales que alcancen las coberturas mínimas, consiste en reorientar los recursos de regalías a otros proyectos de inversión contenidos en el plan de desarrollo, diferentes de los requeridos para lograr las coberturas mínimas.

De las entidades territoriales que actualmente son beneficiarías de recursos de regalías y compensaciones, ninguna ha logrado cumplir todas las coberturas mínimas establecidas en el Plan Nacional de Desarrollo 2006-2010 (Artículo 120 de la Ley 1151 de 2007) en los sectores de: educación, afiliación a salud, mortalidad infantil, agua potable y alcantarillado.

\subsubsection{Incorrecta utilización de los recursos de regalías}

En desarrollo de las labores de interventoría administrativa y financiera, el DNP detecta la comisión de presuntas irregularidades en la utilización de los recursos, las cuales pueden configurar faltas que generan la imposición de medidas preventivas o correctivas por parte del DNP, y de manera simultánea o independiente constituir faltas disciplinarias, fiscales $y / 0$ penales, cuya investigación y sanción corresponde a los Organismos de Control pertinentes (Procuraduría General de la Nación y Contraloría General de la República) y a la Fiscalía General de la Nación; evento en el cual corresponde a este Departamento trasladar al organismo correspondiente la información constitutiva de la presunta irregularidad para que la respectiva entidad adelante el trámite al que haya lugar.

Las interventorías administrativas y financieras contratadas por la Comisión Nacional de Regalías (entidad liquidada), tenían como objeto contractual verificar que la ejecución, distribución y destinación de los recursos de regalías y compensaciones, así como de las asignaciones provenientes del Fondo Nacional de Regalías para las vigencias 2001-2004, se ajustarán a la Ley. En virtud de lo anterior, se evidenciaron 27.610 presuntas irregularidades contractuales, presupuestales, por problemas financieros, en proyectos y en la documentación, que fueron reportadas a los Organismos de Control y/o Fiscalía General de la 
Nación según corresponda. En este sentido, se pudo observar las entidades con mayor número de irregularidades reportadas, destacándose los departamentos de Santander, Casanare, Córdoba, La Guajira, Cesar, Sucre y Huila.

\section{LA PROPUESTA DE REFORMA CONSTITUCIONAL}

\section{Gráfico 1. Propuesta de Ahorro del Sistema General de Regalías}

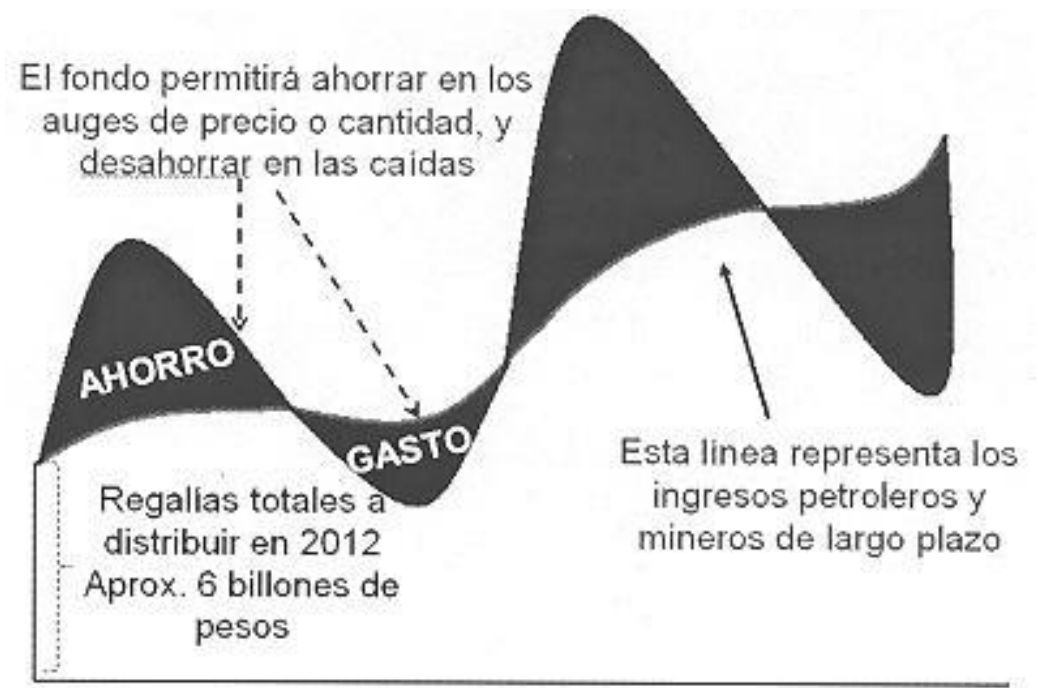

Fuente: Ministerio de Hacienda

El objetivo que se busca con la modificación al régimen actual de regalías y compensaciones es el de utilizar recursos que se espera sean crecientes, por efecto de la dinámica de la actividad minero energética, para impulsar el crecimiento regional, la equidad entre regiones, disminuir los índices de pobreza y aumentar la competitividad del país. Como se dijo arriba, tres criterios de equidad deben guiar el diseño del nuevo uso de las regalías: la equidad regional, la equidad social y la equidad intergeneracional.

Partiendo del principio de que el subsuelo de la Nación pertenece a todos los colombianos, los ingresos que se generen por su explotación también deberán ser distribuidos entre toda la población. Desde luego, no se pretende despojar a las regiones productoras y a aquellas que presentan algún daño ambiental por estar en zonas de actividad minera; pero sí se espera que los recursos generados por esta actividad contribuyan al desarrollo regional del país, privilegiando a las regiones más pobres, a través de un fondo de Compensación Regional que premie la asignación de recursos a éstas

El Gobierno Nacional buscó plantear una opción de organización regional para que las entidades territoriales opten por la mejor alternativa de gestión de los recursos que se generen por cuenta de las regalías en beneficio del desarrollo regional y del país. Se planteó entonces escenarios flexibles que promueven el 
mejoramiento en la capacidad de gestión de las entidades territoriales, evitando la duplicidad de tareas y los esfuerzos aislados de territorios muy próximos en sus condiciones, generando economías de escala que facilitan menores costos y mayores niveles de ahorro a sus presupuestos, y recalcando también los principios de eficiencia y de racionalidad en el gasto como parte elemental del concepto de buen gobierno.

Ante el importante crecimiento de los recursos derivados de la producción de hidrocarburos y por ende del ingreso fiscal derivado de la renta petrolera (impuestos, dividendos y regalías), el Gobierno Nacional propuso al Congreso de la República el rediseño del marco constitucional que hoy rige la distribución de las regalías en Colombia en especial de los artículos 360 y 361 de la Constitución Política, reemplazando el esquema actual de las regalías por el Sistema General de Regalías.

La reforma constitucional propuesta se fundamentó en cuatro principios: 1) el ahorro para el futuro; 2) la equidad regional, social e intergeneracional; 3) la competitividad regional y 4) el buen gobierno.

Para conseguir estos objetivos se crea el Sistema General de Regalías conformado por la totalidad de las regalías percibidas por el Estado, producto de la explotación de recursos naturales no renovables el cual se distribuirá de la siguiente manera:

- Participación del Fondo de Ahorro y Estabilización, compatible con las reglas de ahorro del Gobierno Nacional consignados en la regla fiscal y las normas de disciplina fiscal.

- Participación del Fondo de Competitividad Regional.

- Participación regional de los departamentos, municipios y distritos en cuyo territorio se adelanten explotaciones de recursos naturales no renovables, así como los puertos marítimos y fluviales por donde se transporten dichos recursos 0 productos derivados de los mismos.

- Ahorro pensional territorial.

- Recursos para ciencia, tecnología e innovación.

De manera concreta, en cuanto a la propuesta normativa, el artículo 360 que se presenta consagra el derecho que tiene el Estado a participar de la explotación de los recursos naturales no renovables a través de las regalías y las compensaciones.

Así mismo, refiere a una ley que deberá ser de iniciativa gubernamental la administración, ejecución, control, uso eficiente, destinación, funcionamiento del Sistema General de Regalías y las condiciones en las que los beneficiarios participarán de sus recursos. En tal sentido, será el Legislador quien determine, dentro del marco definido por el nuevo orden constitucional, las condiciones específicas en las que los beneficiarios de regalías y compensaciones tendrán derecho a participar de las mismas. 
La propuesta que se presenta para la modificación del artículo 361 conlleva, como aspecto más relevante, la eliminación del Fondo Nacional de Regalías (FNR) y la constitución del Sistema General de Regalías (SGR) que se compone, por una parte de dos fondos, el de Ahorro y Estabilización y el de Competitividad Regional; y de la otra, por los actuales beneficiarios de los recursos de regalías y compensaciones y por recursos para inversión en ciencia, tecnología e innovación en las regiones. Todo esto será asignado una vez se hacen los descuentos de Ley correspondientes a los aportes a pensiones territoriales.

El Fondo de Ahorro y Estabilización, se financiará con parte de los recursos de regalías y compensaciones y tendrá como objetivo general absorber las fluctuaciones en el valor de las mismas, con el propósito de reducir la volatilidad en los ingresos de los beneficiarios. En cuanto a el Fondo de Competitividad Regional, se compone del Fondo de Compensación Regional y del Fondo de Desarrollo Regional; con el primero se pretende cumplir con el principio de equidad social, de forma que la distribución de los recursos favorezca a las regiones más pobres del país, asignándole una alta prioridad a las zonas costaneras y las situadas a lo largo de nuestras fronteras, para que alcancen un nivel de desarrollo equiparable al del promedio nacional. Con el Fondo de Desarrollo Regional, se pretende dar cumplimiento al principio de equidad regional. Dicho fondo debe derivar en un diseño de distribución del ingreso que favorezca el desarrollo de todos los Departamentos y municipios. Este concepto de equidad regional fortalece la integración de diversas entidades territoriales en proyectos comunes, y otorga una mayor flexibilidad a dichas entidades para la inversión de los recursos y priorización de proyectos y necesidades.

Los actuales receptores de los recursos de regalías tendrán una asignación específica de los recursos del SGR, adicional a aquella a la que tienen derecho por participar en el Fondo de Competitividad Regional. Dicha asignación tendrá un desmonte gradual pero no total, el cual será definido por la Ley. Se hace expresa la destinación para proyectos de ciencia, tecnología e innovación del $10 \%$ del Sistema General de Regalías, descontado el valor destinado al Fondo de Ahorro y Estabilización y los recursos destinados al ahorro pensional de las entidades territoriales. Su ejecución se hará de conformidad con la ley.

La norma constitucional propuesta define los usos en los cuales se pueden invertir estos recursos que, como se dijo, serán en primer lugar, para proyectos de desarrollo económico, social y de infraestructura regional; e inversión en ciencia, tecnología e innovación; así mismo, se mantiene el ahorro que hacen las entidades territoriales a efectos de financiar el pasivo pensional que tienen a su cargo.

Las anteriores motivaciones se materializaron en al Acto legislativo No 5 de 2011 "Por el cual se constituye el Sistema General de Regalías, se modifican los artículos 360 y 361 de la Constitución Política y se dictan otras disposiciones sobre el régimen de regalías y compensaciones". 


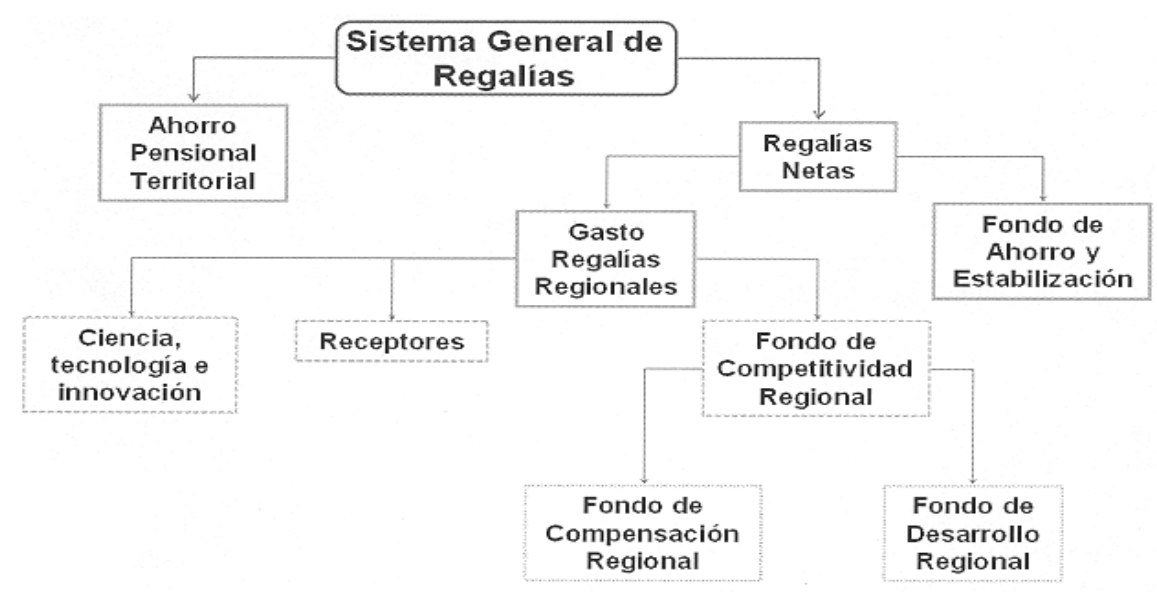

\section{REFERENCIAS BIBLIOGRÁFICAS}

Acto legislativo No 5 (2011). "Por el cual se constituye el Sistema General de Regalías, se modifican los artículos 360 y 361 de la Constitución Política y se dictan otras disposiciones sobre el régimen de regalías y compensaciones".

Banco de la República. (2011). Comportamiento macroeconómico. Serie históricas. Bogotá.

Cuintaco, B. (2010). Vacunas contra la enfermedad holandesa. Carta Petrolera. Bogotá.

Colombia, Departamento Nacional de Planeación (2010), "Distribución de participaciones de regalías de Hidrocarburos", Bogota.

Colombia, Ministerio de Hacienda y Crédito Público (2010), "Las bonanzas externas preceden períodos de recesión", Bogotá.

Colombia, Ministerio de Minas, DGPM (2010), "Proyección de precios del sector minero-energético", Bogotá.

Echeverry, J. C. (2002) ¿Qué aprendimos de la crisis? en Las Claves del Futuro. Bogotá: Editorial Oveja Negra.

Fondo Monetario Internacional, AIE, The Economist, Ecopetrol, ACP Shabsigh, G. e llahi, N. (2007). "Looking beyond the fiscal: Do oil funds bring macroeconomic stability". Working Paper 07/96. International Monetary Fund

Junguito, R. (1996. )Manejo de bonanzas cafeteras. (Management of coffe bonanzas) en Borradores Semanales de Economía \# 53,. Bogotá: Banco de la República. 
Lederman, D. y Maloney, W. (2007). "Ni maldición ni destino: Introducción a los recursos naturales y el desarrollo" ["Neither curse nor destiny: introduction to natural resources and development), en Lederman, D. y Maloney, W. (2007), eds. "Recursos Naturales: Ni Maldición ni Destino". (Natural Resources: Neither Curse nor Destinty). Banco Mundial.

Montenegro, S. (1996) Una década de choques externos cafeteros en Colombia. (One decade of external coffee shocks in Colombia). Bogotá: Oficina de asesores cafeteros.

Tomell, A. y Lane, P. (1999). "El Efecto Voracidad" ("The Voracity Effect). American Economic Review 88 (5): 22-46.

Urrutia, M., y Suescún, R. (1993). Las bonanzas cafeteras y la enfermedad holandesa en Colombia en Cusiana: un reto de política económica. Bogotá: Banco Mundial/ Departamento Nacional de Planeación. - p. 228-253. 